\title{
PSYCHE
}

\begin{tabular}{lll} 
Vol. 87 & 1980 & No. 3-4 \\
\hline
\end{tabular}

\section{THE NATURAL HISTORY AND BEHAVIOR OF THE BOLAS SPIDER \\ MASTOPHORA DIZZYDEANI SP. N. (ARANEIDAE)}

\author{
By William G. Eberhard ${ }^{1}$ \\ Smithsonian Tropical Research Institute and \\ Departamento de Biología, \\ Universidad del Valle, Cali, Colombia
}

\section{INTRODUCTION}

The unusual hunting techniques of the bolas spiders of the tribe Mastophoreae (Mastophora, Dichrostichus, and Cladomelea) were described long ago (Hutchinson 1903, Longman 1922, Akerman 1923). These spiders make a large sticky ball on the end of a short thread, and swing the ball at passing insects while hanging on another short, horizontal "trapeze" line. Probably because the spiders are difficult to find, however, little has been done since to solve the problems which these first observations raised. Gertsch (1955) gives a complete and clear résumé of what had been discovered of the biology of the entire group to that date.

A recent study of an undescribed species of Mastophora which included observations of the behavior of both the spider and its prey plus extensive series of prey has finally confirmed the suspicion of the early naturalists that Mastophora lures its prey with a volatile substance which mimics the sex attractant pheromone of virgin female moths (Eberhard 1977). The present paper gives a taxonomic description of the species on which this work was done and presents

\footnotetext{
${ }^{1}$ Present address; S.T.R.I. and Escuela de Biología, Universidad de Costa Rica, Ciudad Universitaria, Costa Rica.

Manuscript received by the editor December 22, 1980.
} 
further observations on other aspects of its natural history and behavior, including web forms and their construction, the structure and function of the sticky ball, variations in prey species, egg sac construction behavior, and rates of egg sac production. These observations seem to link Mastophora to both araneids such as Cyrtarachne, Poecilopachys, and Pasilobus which spin more nearly typical orb webs, and to the completely webless Celaenia and Taczanowskia.

\section{Methods ANd Study Sites}

The main study site and the observation methods are described in Eberhard, 1977. The spiders were sedentary, seldom moving more than $10-20 \mathrm{~cm}$ in a night and usually returning day after day to the same daytime resting site where a pad of silk gradually accumulated. These sites were extremely exposed; one was on the barb of a barbed wire, and others were on fence posts, the upper surfaces of leaves, etc. in an open field. During the day in Cali the spiders sometimes experienced temperatures of up to at least $42^{\circ} \mathrm{C}$ combined with brisk ( $>10 \mathrm{kmph}$ ) winds.

Additional observations were made in open areas near the edge of Lago Calima (el. $1400 \mathrm{~m}$ ) in grassland with scattered small bushes and trees, where spiders were relatively common in September, 1977, but absent in January, 1979.

Unless otherwise noted, all descriptions of behavior refer to observations of mature females.

\section{Mastophora dizzydeani new species} Figure 1-9

Dr. Willis Gertsch kindly studied male and female specimens, and stated (in litt.) that "I am confident that it represents an undescribed species." Like Dr. Gertsch, I have been unable to match this species to any published description, and keeping in mind the overworked state of most spider taxonomists plus the parasitic relationship which behaviorists and ecologists generally enjoy with them, will undertake the description of this new species.

Etymology. Since this spider's livelihood depends on throwing a ball fast and accurately, it seems appropriate to name it in honor of one of the greatest baseball pitchers of all time, Jerome "Dizzy" Dean.

All measurements in $\mathrm{mm}$; colors in parenthesis from living spiders. 
Female: The measurements of the holotype female from Cali, Colombia, are as follows: total length 15.32, carapace 5.44 long, 6.29 wide; abdomen 10.78 long, 15.99 wide (Figs. 1-3).

Carapace mahogany brown, darkest on sides and the posterior declivity, without noticeable hairs. Sternum yellow-brown in central areas and brown at margins; labium and endites brown with white on margins nearest mouth; coxae and legs brown, the first leg weakly annulated with two bands of light color on femur, three on tibia, and two on metatarsus, similar markings on other legs. Abdomen

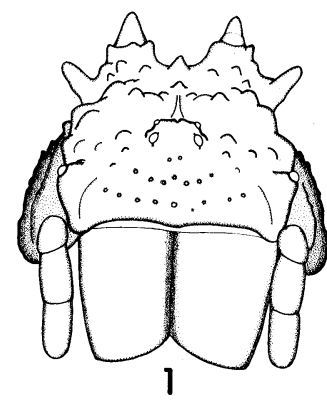

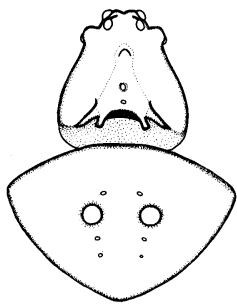

5

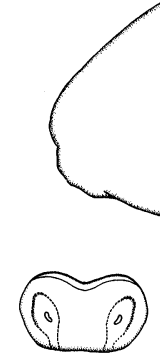

4
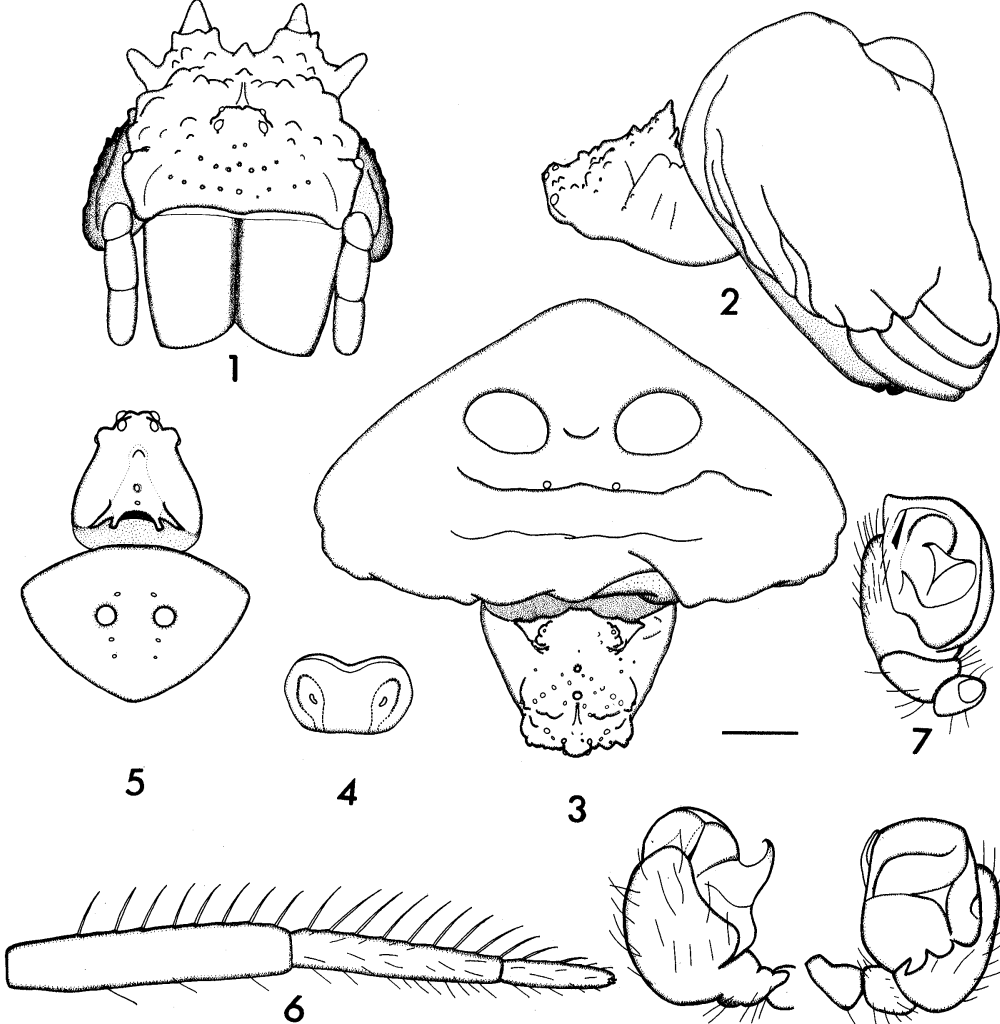

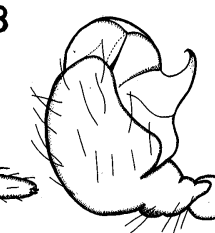

8

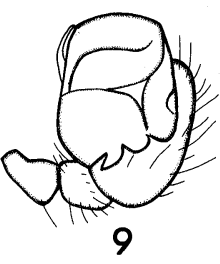

Figs. 1-9. Mastophora dizzydeani new species. 1. Female cephalothorax, anterior view without appendages. 3. Female, dorsal view without appendages. 2. Female, lateral view without appendages. 4. Epigynum, subcaudal view. 5. Male, dorsal view without appendages. 6. Male, right leg I dorsal view. 7-9. Male palpus. 7. Ventral view. 8. Lateral view. 9. Dorsal view 
yellowish (white) with a greyish-brown (dark green with brown tinge) band across the anterior margin with grey (dark green) on the anterior margins of the shoulders and a dark band extending to base; irregularly shaped intercalations of white along the anterior margin of the band. Three pairs of sclerotized depressions (in addition to many scattered minor ones) of which the first pair between the humps is dark brown and more conspicuous. Venter of abdomen whitish (yellow) between epigastric furrow and the brownish spinnerets, with a darker central area.

The carapace about as long as wide, widest posteriorly, rounded on the sides, the pars cephalica at the posterior eye row more than half as wide as carapace $(3.42 / 6.34)$. Pars cephalica subtriangular as seen from side, the occipital horn bifurcate apically, separated by deep rounded depression, and greatest width of horns more than half of width of carapace. Pars cephalica with well developed warts and cones which are mostly restricted to this area of carapace. Lateral eyes of each side on a single projecting cone and the four median eyes on a single, less pointed elevation. Clypeus vertical, equal in height to about 3-4 diameters of anterior median eye. Anterior eye row slightly procurved, posterior row slightly more so. Anterior medians separated by 2.3 diameters, posterior medians by 3.3 diameters; anterior medians from anterior laterals by 8 diameters, posterior medians from posterior laterals by 8.7 diameters. Median ocular quadrangle broader than long (ratio 1.49:1) and front eyes larger.

Chelicerae bluntly conical, the upper margin with three sharp teeth, the middle one longest, lower margin with one tooth. Sternum subtriangular slightly longer than wide (ratio 1.13:1), broadly emarginate in front with rounded point opposite the posterior margin of each coxa. Posterior coxae separated by $1 / 4$ width of fourth coxa. Labium broader than long (ratio 2.12:1) with central point projecting somewhat at tip and extending to about $1 / 3$ of distance to tips of parallel endites.

Legs clothed with fine hairs.

\begin{tabular}{lrrrr} 
& I & II & III & \multicolumn{1}{c}{ IV } \\
Femur & 5.33 & 4.27 & 2.83 & 4.07 \\
Patella & 2.92 & 2.53 & 1.49 & 1.94 \\
Tibia & 4.88 & 3.42 & 1.91 & 2.95 \\
Metatarsus & 5.05 & 3.09 & 1.71 & 2.67 \\
Tarsus & 1.40 & 1.01 & .79 & .73 \\
Total & 19.58 & 14.32 & 8.73 & 12.36
\end{tabular}


First leg with metatarsus much thinner than tibia and slightly curved, median claws large and strongly curved.

Abdomen broad and subtriangular as seen from above, shallowly emarginate anteriorly and broadly rounded on sides, presenting a pair of clearly defined but not large tubercles slightly posterior and median to the shoulder humps. Abdomen overlapping carapace about to the horns, highest just anterior to the tubercles and declining steeply behind, with the caudal portion rounded. Abdomen hairless except for ventral surface anterior to spinnerets. Deepness of wrinkles along sides related to how recently spider oviposited.

Spinnerets with apical segments short and subconical. The epigynum is illustrated in Fig. 4.

Male: Total length of holotype from Lago Calima, Valle, Colombia is 1.81; carapace .87 long; abdomen .91 long and 1.35 wide.

Coloration of carapace brown (reddish orange) with longitudinal white stripe forming dorsal triangle, eyes lighter. Abdomen white with scattered small grey blotches at anterior dorsal margin. Three pairs of large sclerotized depressions present, and tubercles posterior to first pair and separated slightly more than the depressions.

The palpus is illustrated in Figs. 7-9.

Type Localities: Female holotype from field on Melendez campus of Universidad del Valle at southern edge of Cali, Colombia. Male holotype from field at eastern edge of Lago Calima, near Darien, Valle, Colombia.

Distribution: Western Colombia in Departamento Valle del Cauca. $1000-1400 \mathrm{~m}$ el. in western range of Andres.

Other Records: mature female, other mature males, several juveniles from type locality of male holotype.

\section{Natural History and Behavior}

Web construction and prey capture

The form of the bolas and its construction were basically the same in M. dizzydeani as those of M. cornigera as described by Hutchinson (1903) and Gertsch (1947). A number of details were different, however, perhaps due to species differences, and are described below.

As the spider moved back and forth on the horizontal (trapeze) line prior to starting a bolas (Fig. 10a), she did not reinforce the line, but rather repeatedly broke it, and reeled up the old line as she payed out a new one behind, her body thus forming a bridge between the two lines. She often descended somewhat as she broke the line, and waved 

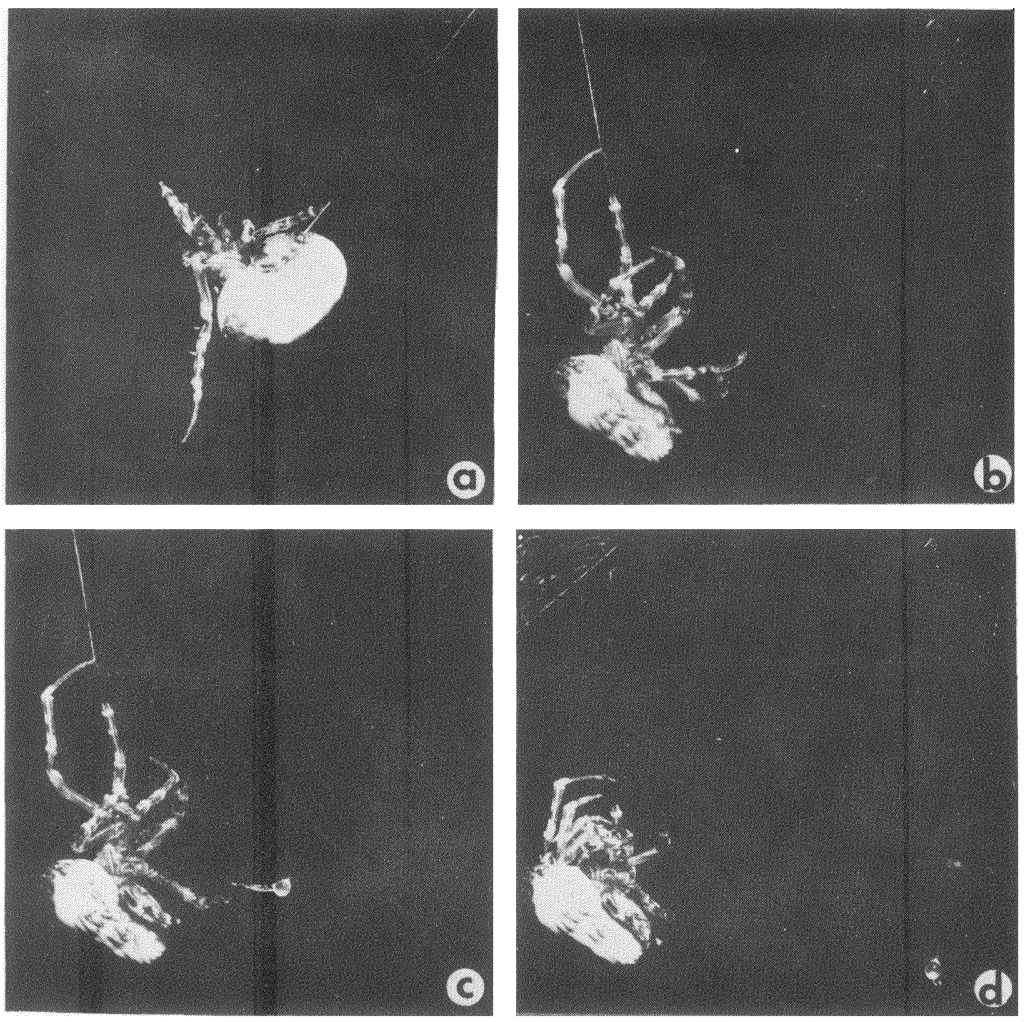

Fig. 10. Construction of a sticky ball. A. Spider moves horizontally, waving her front legs actively in the space where she will produce and swing her bolas. Probably this behavior serves to sense the presence of objects which would interfere with hunting behavior. B. Spider hangs from the horizontal trapeze line and begins to pull sticky silk from her spinnerets onto the bolas line which is attached above to the trapeze line. C. Spider continues to produce sticky silk and the sticky ball grows. D. The last of the sticky silk has been produced and it is slowly absorbed into the ball as the ball hangs free. The spider then walks across the trapeze line, grasps the bolas line, and assumes the hunting posture. 
her front legs actively as she moved (Fig. 10a), perhaps in order to sense the presence of objects beneath her future hunting site. As she produced the ball of sticky material at the end of the bolas line (Fig. 10b-d), it did not seem that she swept viscid material along a central line, but rather that a line as well as viscid material was pulled out with her IV legs. This impression was confirmed by microscopic examination of completed balls which showed large accumulations of thread (below). About 80-100 pulls with alternating legs IV were performed before the ball was complete, rather than $16-20$ as with $M$. cornigera. Typically the spider began with shorter and quicker strokes, and then slowed as the ball began to form. When the ball was finished, it appeared that the silk simply ran out rather than that the spider somehow cut the line with one leg IV. The production of a ball took only 1-2 minutes from start to finish.

On several occasions spiders assumed predatory positions without balls (Fig. 11) some of these after a ball being constructed was experimentally removed or became stuck to a leg and was ingested; I assumed that these spiders were hunting since some moths approached them, but I never saw a prey capture. Hunting without first making a ball seemed to be associated with particularly windy evenings, but no careful measurements were made.

Smaller, immature spiders made balls less often. One female which was an estimated 3-4 moults from maturity was seen hunting both

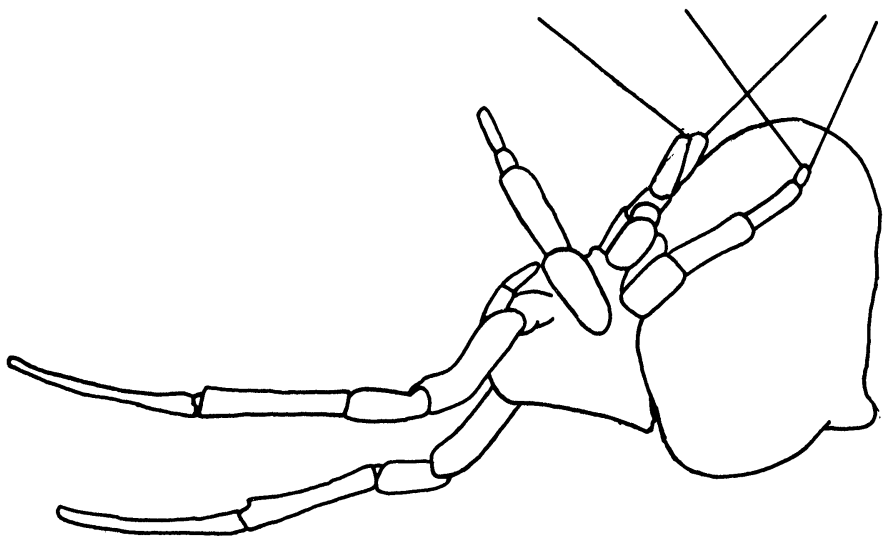

Fig. 11. A mature female M. dizzydeani in hunting position without a ball, with both legs I extended anteriorly (seen from the side and slightly below-drawn from a photograph). 


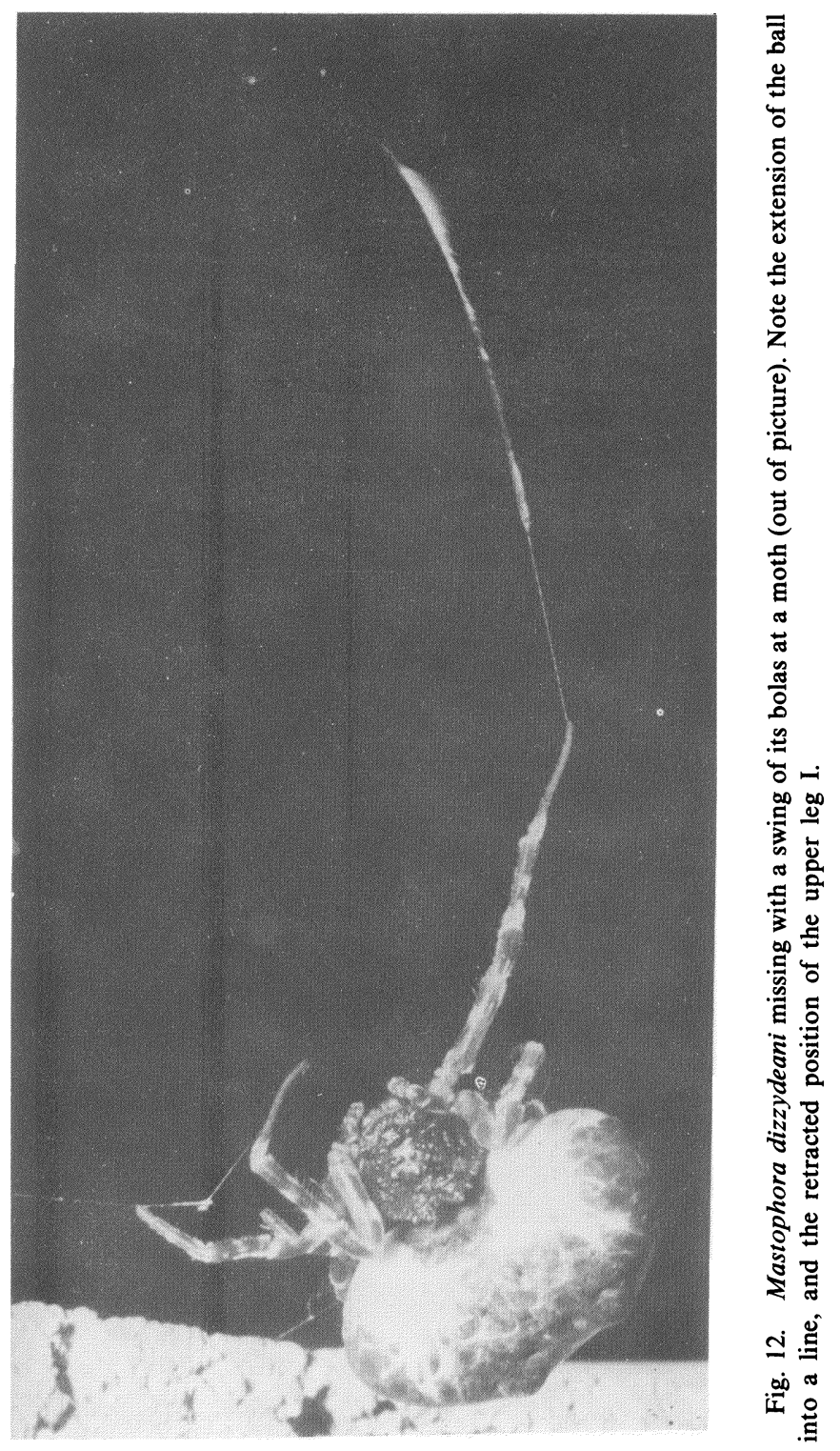


prey with one leg IV, climbed onto the trapeze line, and turned the moth so its anterior end was at her mouth and fed.

Several variations on this general scheme were observed. On some occasions a spider which had captured a moth did not feed immediately, but fastened it to the trapeze line, spun a new ball, and resumed hunting; in one case a spider had three prey on the trapeze line when she caught a fourth. Longman (1922) observed a Dichrostichus magnificus which also temporarily stored prey on the trapeze line. In no case did I see an extended coating along the bolas line as has been observed with $M$. bisaccata (Gertsch 1955) and $D$. magnificus (Longman 1922), and only one of an estimated 60 balls observed was double. On one occasion however I saw an even stranger trap. One particularly warm and windless evening a spider had an unusually long trapeze line which had three different balls hanging from it. The spider was at one end of the trapeze in a predatory stance, and did not hold a ball. The spider soon ate the balls, and later the same night made a single ball and held it with one leg in the usual fashion.

Balls were ingested if after a period of waiting no prey were captured; such lapses averaged 24 min (range 14-41, $N=8$ ). Usually the spider did not make another ball immediately after ingesting an earlier one, but rested immobile for up to an hour or more.

\section{The BaLl}

Moths are difficult prey for web spiders to capture since their abundant and easily detached scales more or less insulate them from sticky traps (Eisner et al. 1964), and some araneids have evolved special attack behavior towards them to offset this defense (Robinson 1969, Robinson, Robinson and Graney 1972). It is thus surprising that $M$. dizzydeani was able to catch moths regularly with a sticky trap, and the structure and function of the sticky ball assume particular interest.

The balls of $M$. dizzydeani were largely liquid. When touched to a piece of filter paper, a ball immediately wet an area two to three times its diameter and, to the naked eye, disappeared. When touched to a nonabsorbant object like a glass slide, the ball remained visible as a mass of jelly-like material surrounded by a pool of liquid (Fig. 13). That the ball's wetness is essential to its stickiness was shown by taking a newly made ball away from a spider and letting it hang free at 


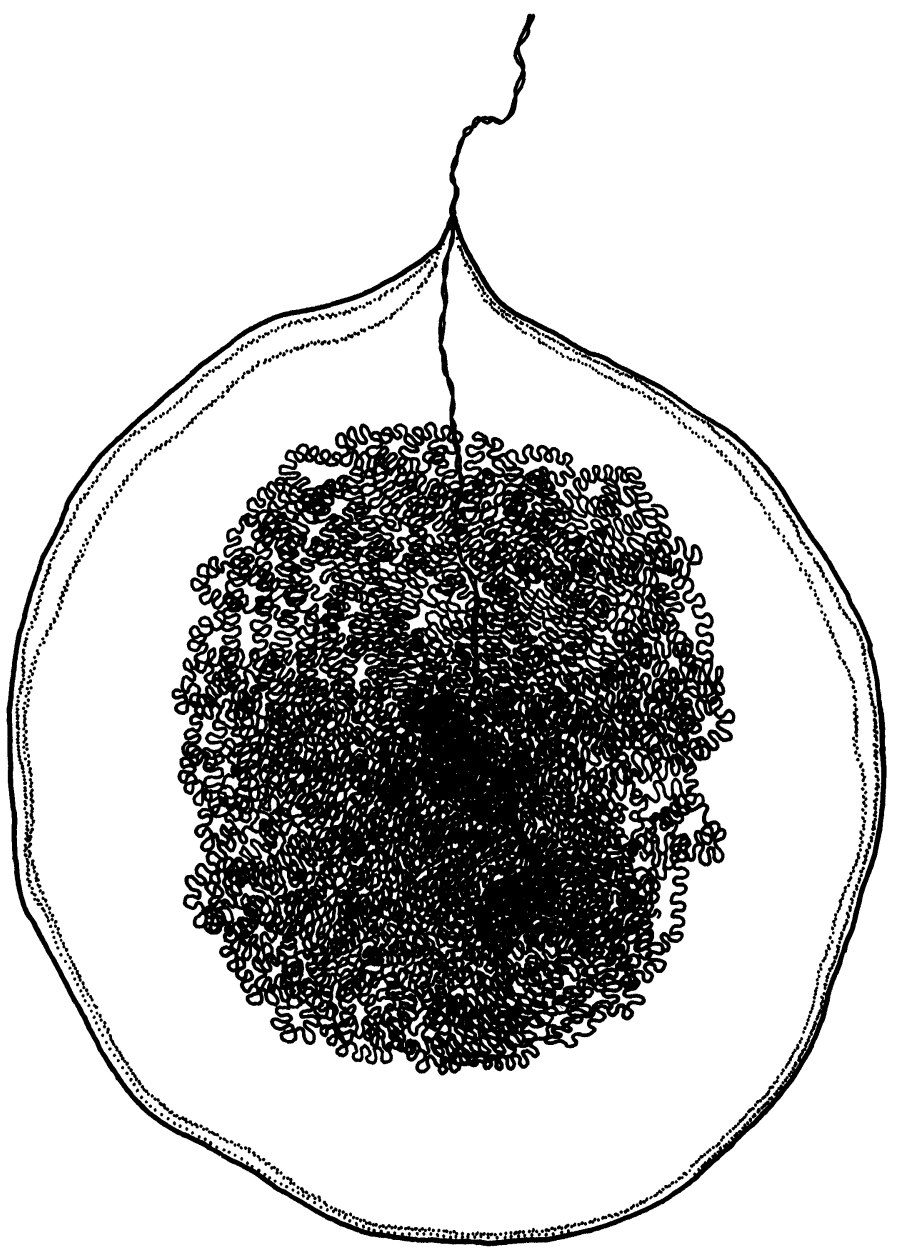

Fig. 13. The internal structure of a sticky ball (diagrammatic) which was lowered onto a glass slide, showing the apparent layers of material of different viscosities near the edges, and the mass of folded thread in the center (regularity of folding is overemphasized). 
the hunting site for 90 minutes. At the end of this time its size was substantially reduced (Fig. 14 -an estimated $40 \%$ loss of volume) and it was no longer sticky. The spiders' ingestion of balls after about 30 minute intervals thus probably served to insure that the ball is sufficiently sticky. This agrees with Hutchinson's observations of the balls of $M$. cornigera. The reduction in size contrasts with the almost complete lack of shrinkage of the balls of adhesive on the sticky spirals of the orbs of araneids such as Metazygia sp., Leucauge sp.,
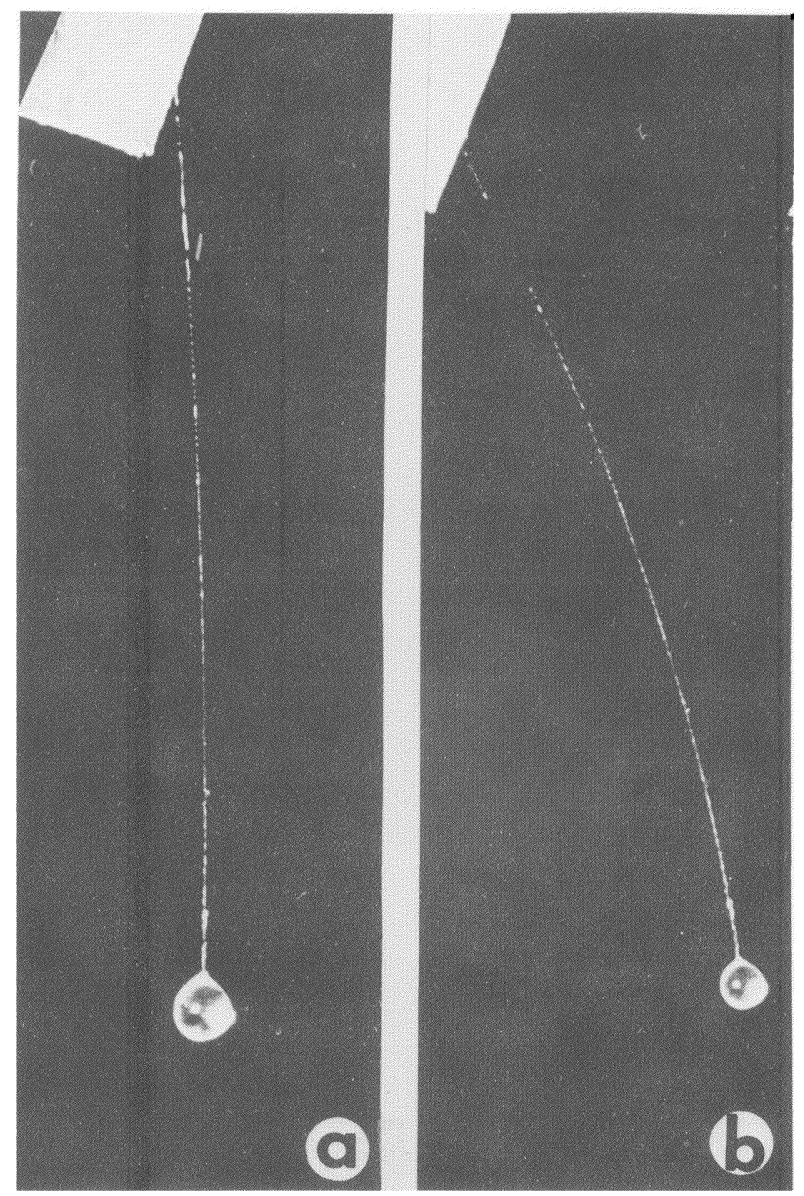

Fig. 14. Shrinkage of a sticky ball due to evaporation: A. a freshly made ball; B. the same ball 90 minutes later. 
and Gasteracantha cancriformis (Eberhard in prep.), and again serves to emphasize the unusually fluid nature of Mastophora's adhesive.

Spiders never discarded balls, always carefully ingesting them even when they accidentally stuck to their own bodies (observed three times) or to nearby objects (observed once-to a cardboard windscreen held near the spider). In addition to the obvious conservation of nutrients which this represents, it may also be important in the conservation of water, since the spiders sometimes go for long periods without drinking and also endure high temperatures at exposed sites during the day (above).

Cursory examination of balls on glass slides showed that their internal structure was complex, and consisted of a mass of curled or folded fibers which was embedded in a viscous matrix which was in turn surrounded by a less viscous layer (Fig. 13). More refined observations by R. W. Work (pers. comm.) showed that the folded "spring" fibers are noodle-like ribbons which are nearly rectangular in cross section (Fig. 15), with only slightly rounded corners and slight bulges on their flat sides. He reports as follows: "The dimensions of two samples of these fibers from Mastophora dizzydeani were $10.7 \times 3.4 \mu \mathrm{m}$ and $10.0 \times 3.2 \mu \mathrm{m}$. A sample from a closely related species from Costa Rica gave $11.4 \times 4.3 \mu \mathrm{m}$. They are possessed of axial birefringence, being of the same order of magnitude $(0.005-0.007)$ in planes perpendicular to both thick and thin axes of their cross sections. In this way they differ markedly from the elastomeric baselines of the sticky spirals of araneid orb webs, which are birefringent in neither the non-extended nor extended states. It follows that the bolas throwing and recovery phenomena are not based on elastic properties. Rather, the combination of rectangular cross section (typical of a steel spring), folded or sinusoidal configuration while at rest, and axial molecular orientation (as evidenced by bifrigence) is the basis of the springiness. The spring fibers are also different from the fibers making up the line from which the ball was suspended since these latter, which are also birefrigent (values approximated .02-.03, typical for lines from the major ampullate glands of other arachneids), were round ( $4-5 \mu \mathrm{m}$ in diameter) as is typical of other spider fibers. The details of the junction between the bolas and the suspension line could not be resolved, although it appears that spring fibers may be present in the 'bundle' near the end of the line." 
The ball lost most of its adhesiveness after a single long extension, but shorter extensions appeared to be reversible. In one case a ball taken from a spider was touched lightly against a nearby object and then pulled away gently. A small mass of "liquid" stayed on the object, and was connected to the ball by a thin, dry thread which was not sticky when touched. When I moved the ball several $\mathrm{mm}$ farther away more of the dry line was drawn out, and when I moved it back this line drew back into the ball. This was repeated several times with identical results. Probably the dry line was one of the folded threads, and its immediate withdrawal into the ball when tension was lowered was due to its tendency to resume a folded configuration. In other cases a greater quantity of material was stuck to an object and when the object was moved away the entire ball rather than a single thread stretched with it. Hutchinson (1903) saw similar extraction and withdrawal of line in M. cornigera (in this case the line was the bolas line from which the ball was suspended).

The extensibility of the ball had an unsuspected consequence which was revealed in photographs taken as the spider swung at moths. As seen in Fig. 12, the ball stretched into a line during the

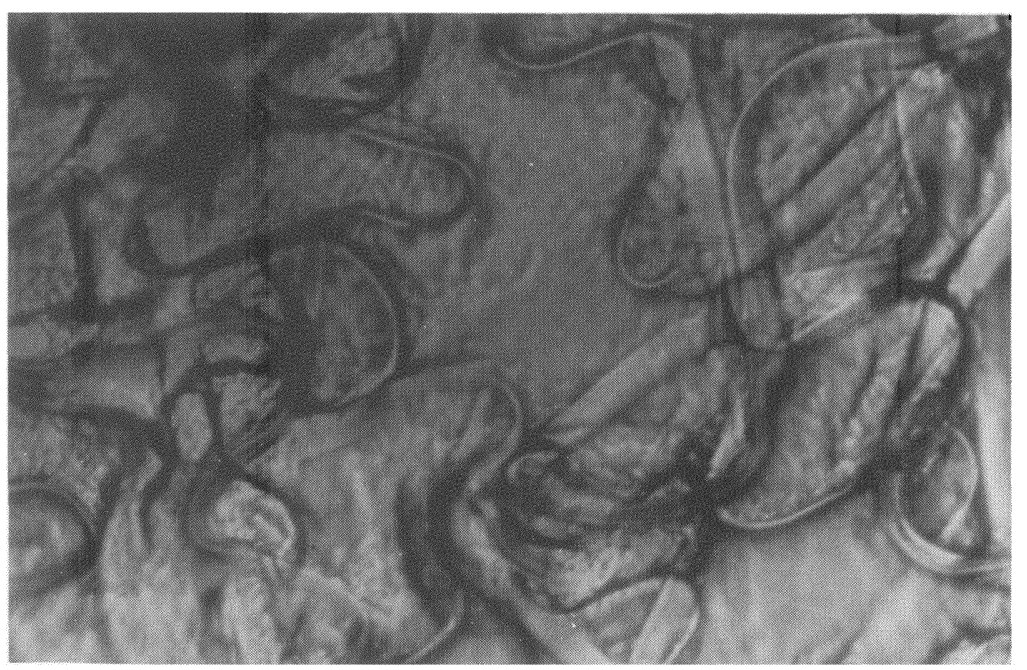

Fig. 15. Micrograph of fibers inside a sticky ball of $M$. sp. near dizzydeani from San José Costa Rica, showing regular folding, and ribbon-like shape of the fibers (unmodified illumination of ball on a glass slide; $10 \mu \mathrm{m}=6.6 \mathrm{~cm}$, original magnification $250 \times$ ). Photograph by R. W. Work. 
swing. The greatest extension observed amounted to about $3.5-4 \mathrm{~cm}$. This change was completely reversible and the recovery was evidently very rapid. I never noticed any elongation after swings by spiders, nor was I able to see any elongation when I myself swung a newly-made ball and looked quickly after each swing. The significance of this property of the ball is probably that it increases the spider's striking distance while maintaining between swings the compact ball form which is essential for quick and accurate strikes. Such use of springlike action is unusual if not unique in animal structures.

In summary, it appears that the ball may function in the following way. The low viscosity liquid is sufficiently wet and abundant to flow past the moth's scales and reach a relatively large area of the cuticle below. The more viscous liquid forms the actual bond to the thread which sustains the moth's weight, and the thread folded inside the ball functions to permit quick, reversible elongations which extend the spider's striking range and perhaps also serves to hold prey once it is hit.

\section{PREY}

The prey caught by a given individual of $M$. dizzydeani are relatively constant, but, as shown in Table 1, there is variation between individuals even at the same site. Some but not all the differences might be due to differences in prey abundances at different times of the year, although casual observations suggest that this was not the case. Small spiders seem to differ radically from larger ones in prey identity, which is expected given the relatively large size of the larger spiders' prey.

Rates of prey capture were estimated from numbers of moths found in sticky traps placed under four mature females' hunting sites; they were certain underestimates since several times I saw a spider feeding on a moth in the evening but found no prey in the trap the next morning (probably some prey were blown clear of the traps when they were discarded). A total of 204 moths was found after 100 spider hunting nights (nights dedicated to egg sac construction were not counted), giving an average of 1.85 moths per hunting night. Since the rates of egg sac production were determined for these same four spiders during the same period ( 23 sacs in 219 spider days), these data can be used to test the assumption on which Eberhard (1979) based calculations of prey capture rates-namely that spiders convert 


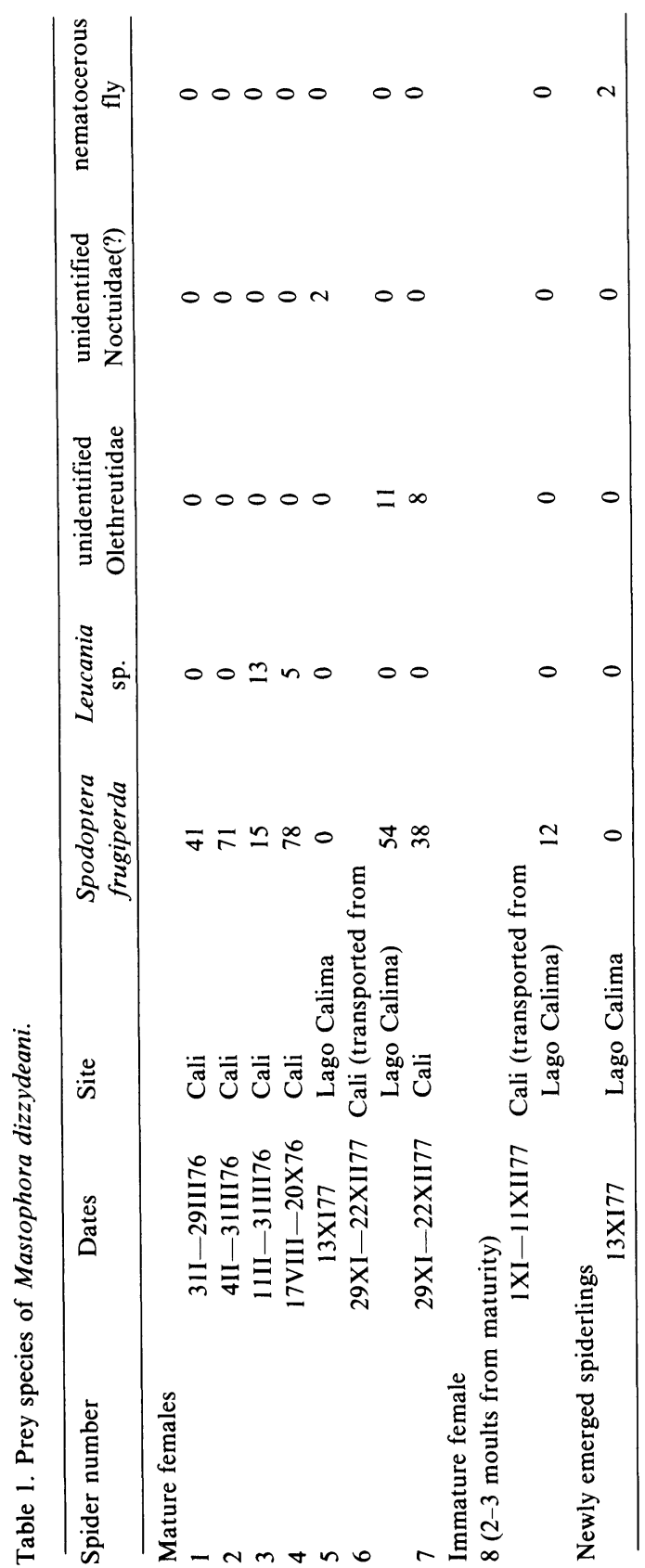


about $25 \%$ of the wet weight of prey captured into eggs. These $M$. dizzydeani captured an average of 15.7 moths per sac; and the average wet weights of moths and sacs were $59.2(\mathrm{~N}=9)$ and $331 \mathrm{mg}$ $\mathrm{N}=1$ ) respectively. This gives $331 \mathrm{mg}$ of eggs resulting from $931 \mathrm{mg}$ of prey, or $35.6 \%$ of prey weight being converted into eggs. These figures are only approximate, especially in light of the small sample of egg sac weights and the underestimates of prey captured. They are close enough to the value used by Eberhard (1979) to encourage belief that the calculations made there are not wildly wrong.

\section{Egg Sac Construction}

Spiders ceased predatory activity as much as 24 hours before ovipositing. Egg sac initiation was seen three times, always between 0:00 and 1:50. As illustrated in Fig. 16 there were three recognizable stages. First the spider made a disc of greyish-white fluffy silk suspended from one side (Fig. 16a). She enlarged this by adding silk to the sides and bottom with a stereotyped dabbing movement: the spinnerets were touched to the edge of the disc, then legs IV lifted the disc up and away, then brought it back down; this cycle was repeated over and over, with several threads being drawn each time. After about five minutes of this the spider held the disc against her ventral surface where it received the ball of yellow eggs which slowly emerged (Fig. 16b,c). The oviposition took approximately five more minutes, and when the ball was complete the spider pulled the sides of the disc around it and fastened them together with more dabbing movements so that the eggs were sewn into a cradle of fluff. She then made more fluff by holding the suspension line with one leg I and slowly treadmilling on the ball, pulling her abdomen away after each attachment so that it "bobbed" back and forth. This then gave way to further treadmilling without the bobbing movement but instead quick $(2-4 /$ sec.) side to side dabs with the abdomen, and the sac began to acquire a smooth outline (Fig. 16d). Within 20 minutes after the eggs had emerged they were no longer visible except for a yellow glow inside the ever-thickening walls when they were illuminated. About 15 minutes later, as the spider continued her treadmilling, the sac began to darken. The final product (Fig. 16e) was somewhat variable with respect to color and details of form, but was very similar to the sacs of M. cornigera and M. bisaccata (Gertsch 1947, 1955). A thick stem which spread into a plane at the top supported a nearly spherical sac which had in some cases small excrescences near the 
midline. The basic color was amber brown, but it was overlaid with irregular patches of first white and then more brown silk. Where white overlaid brown the color was white, but where brown overlaid white an intermediate light brown color was produced. The total result was that the sacs appeared to be covered with irregularly shaped and distributed patches of brown, light brown, and white. As with other Mastophora species (Gertsch 1955) strong lines (with a faint golden tinge) accumulated around groups of egg sacs.
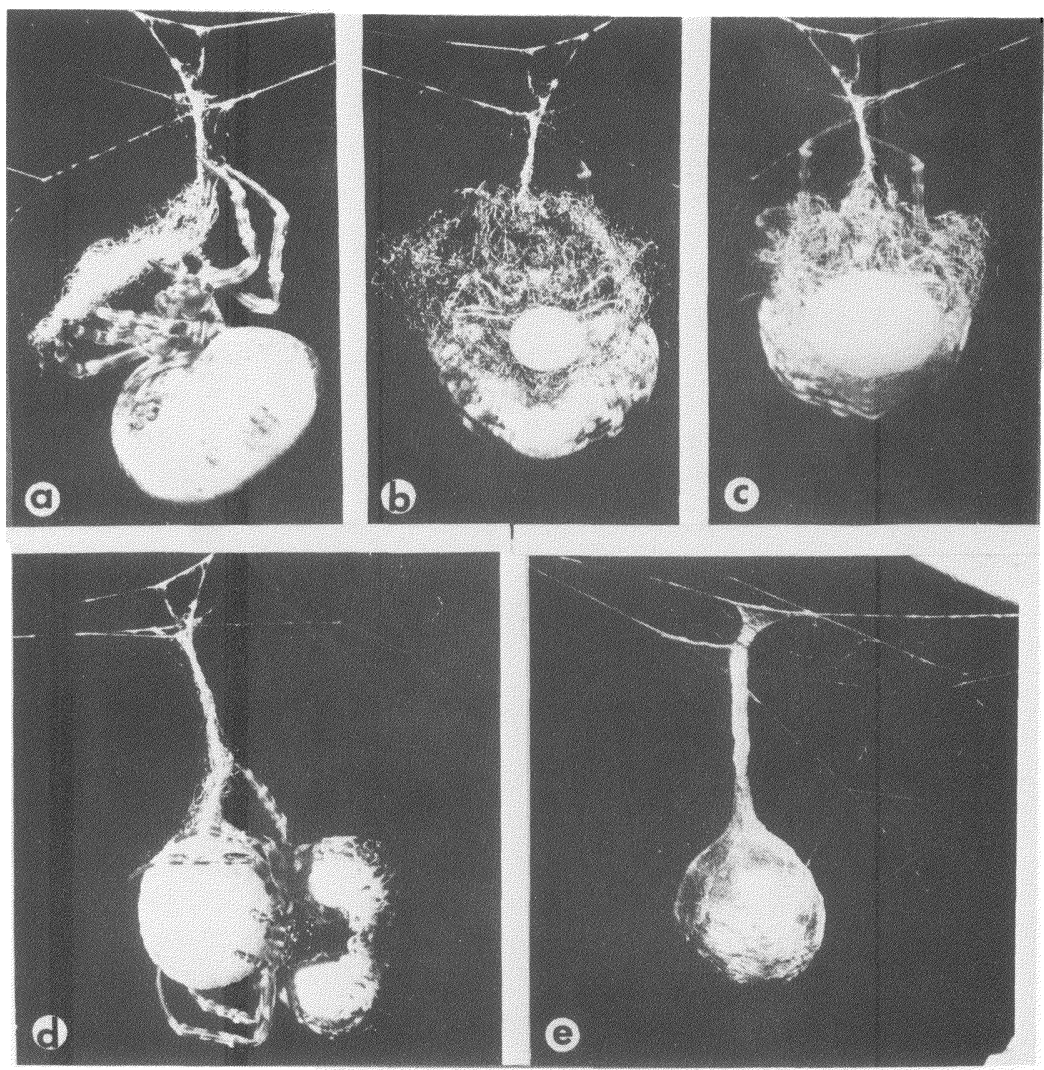

Fig. 16. Egg sac construction. A. Spider spins a loose mat of silk hanging at the end of a reinforced line. B. Mass of eggs begins to emerge. C. Mass has emerged further and is cradled by the mat of silk. D. Spider "treadmills" on sac which has now assumed a smooth outline. E. Finished sac. 
Individual females produced up to eleven sacs. The average time between sacs was 9.5 days ( 23 sacs; range 5-13 days). One representative sac weighed $331 \mathrm{mg}$ and had $826 \mathrm{eggs}(.40 \mathrm{mg} / \mathrm{egg})$.

\section{NEWLY EMERGED SPIDERLINGS}

In some Mastophora species males emerge from the egg sac already mature (Gertsch 1947, 1955), but this was not the case in $M$. dizzydeani. Males of this species emerged an estimated one to two moults from maturity. On several occasions I found spiderlings which had especially swollen abdomens apparently feeding on shrivelled unhatched eggs when I opened a sac. Some shrivelled spiderlings were also seen, and when masses of spiderlings were observed under the microscope I saw that a typical behavior that was associated with the periodic waves of activity that swept through the mass was to "lunge" ventrally one or more times with the chelicerae open and snap them shut. Cannibalistic feeding could result in the growth of spiderlings within the sac, and should be looked for in species like $M$. cornigera in which males normally emerge mature. A suggestion that such cannibalism occurs comes from Gertsch's report (1947) that only about 150 spiderlings emerged from each sac of $M$. cornigera. Since this species is slightly larger than $M$. dizzydeani and thus almost certainly lays more rather than fewer eggs per sac (clutch size is strongly correlated with spider size in Araneidae - Eberhard unpub.), and since $M$. dizzydeani lays on the order of 800 eggs per sac, it is likely that the $150 \mathrm{M}$. cornigera spiderlings resulted from a much larger number of eggs.

The sexes of newly emerged spiderlings could be distinguished by the slightly swollen pedipalps of the males. The sex ratios of samples of spiderlings from three egg sacs were 1:.787, 1:1.09, and 1:1.49 male:female (373 spiderlings, total ratio $1: 1.01)$. This approximation to $1: 1$ is similar to those found by Gertsch (1947) for M. cornigera and Lowry (in McKeown 1952) for D. magnificus.

Spiderlings of both sexes had a row of strong bristles on the prolateral surfaces of the tibiae and metatarsi of legs I and II (Fig. 17) which seemed to be essentially identical to the spines on the same legs of mature males. The spines are apparently soon lost, however, since a third or fourth instar female lacked them. 


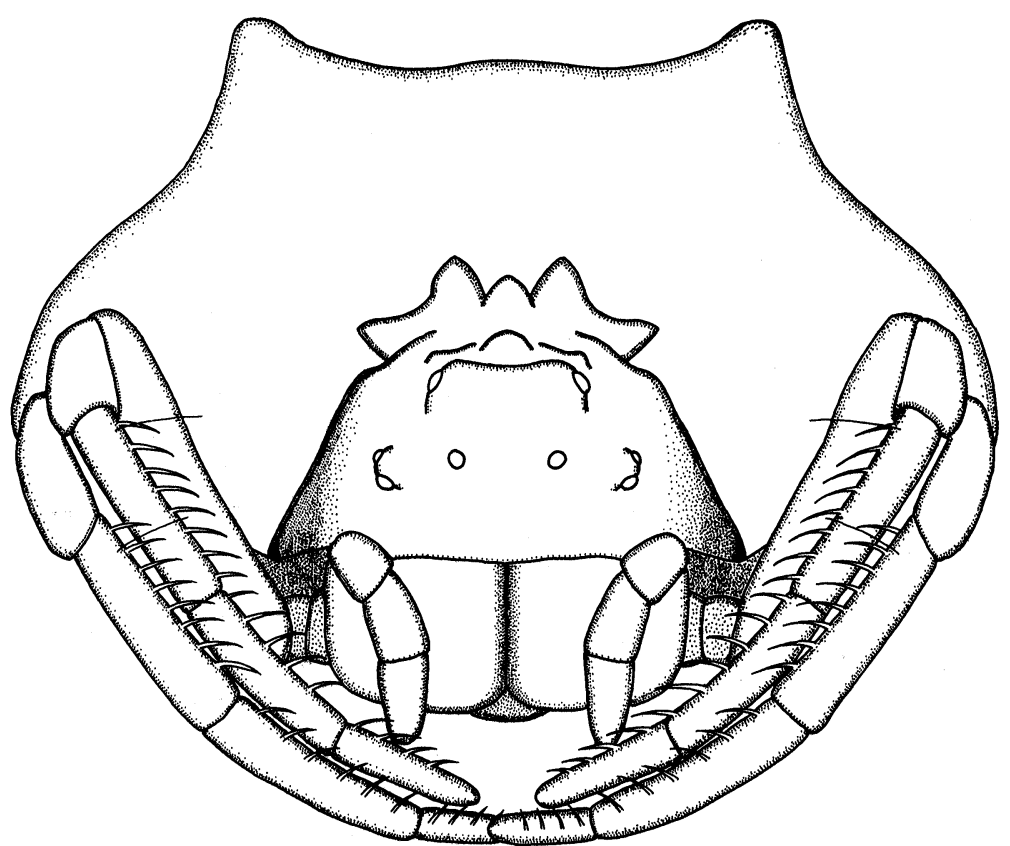

Fig. 17. A third instar female spiderling showing the spines on the prolateral surfaces of the front two pairs of legs.

\section{DEFENSIVE BEHAVIOR}

Bolas spiders are sometimes called "bird lime" spiders because of their supposed resemblance to bird droppings as they rest during the day. Once one has found a spider this resemblance seems a bit farfetched, but my repeated experience during daytime searches for spiders of finding a spider only to have it turn out to be a bird dropping suggest that the spiders' coloring and resting posture (similar to that of M. cornigera-Gertsch 1947) do function to mimic bird droppings.

$M$. dizzydeani did not attempt to flee when disturbed, but simply crouched immobile, even when picked up in the fingers. Gertsch (1947) observed the same behavior in $M$ cornigera. When squeezed gently on the abdomen, $M$. dizzydeani produced a strong, somewhat disagreeable odor reminiscent of those of lampyrid beetles and 
canned string beans. When spiders were observed under the microscope it was clear that the odor was produced by the regurgitation of a drop of cloudy liquid at the mouth. When the disturbance had passed the spider sucked the liquid back in and cleaned its mouthparts and the smell vanished. Hutchinson (1903) also noted that disturbed $M$. cornigera produced an unpleasant odor which came from a drop at the mouth.

\section{Discussion}

Robinson and Robinson (1975) suggested, on the basis of their study of Pasilobus and Clyne's work (1973) on Poecilopachys, that there is an evolutionary series starting with typical orb weavers and passing through Poecilopachys and then Pasilobus to the bolas spiders Mastophora, Dichrostichus, and Cladomelea. They established several links in web architecture and function between Poecilopachys and Pasilobus. The results of this study support this general scheme and indicate that the line can be reasonably extended through the bolas spiders to the webless araneids Celaenia and Taczanowskia. This series does not of course purport to demonstrate that any group is directly descended from any other, but rather refers to increasing specialization of prey catching behavior which diverges in this group of genera from the ancestral construction of typical orb webs.

There are several points of similarity between these observations of M. dizzydeani and the data available for Pasilobus sp. (Robinson and Robinson 1975), Poecilopachys australasia (Clyne 1973), and the related Cyrtarachne sp. (Eberhard unpub.):

A. All actively pull sticky silk from their spinnerets while hanging more or less vertically below a horizontal thread (e.g. Fig. 4B in Robinson and Robinson 1975). This movement is similar to and was probably derived from the pulling movements many araneids make with legs IV as they lay sticky spirals (Robinson and Robinson 1975, Eberhard in prep.). The Robinsons were not certain that thread (as opposed to only vicous material) was being pulled out by Pasilobus, but from their description, personal observations of Cyrtarachne and Mastophora (above), and considerations discussed in Eberhard (1976 and in prep.), this seems to me to be likely.

B The M. dizzydeani web which had several balls hanging from a 
single horizontal thread is similar to a Pasilobus web: if one breaks the low-shear joints at the ends of Pasilobus spanning threads so that they hang from the midline, the webs are nearly identical. The web of Cyrtarachne sp. (Fig. 18) is very similar to that of Poecilopachys, as is its building behavior (Eberhard, unpub.).

C Both M. dizzydeani females and Pasilobuis catch moths almost exclusively. This specialization in $M$. dizzydeani is probably due to the use of moth sex attract pheromone mimics (Eberhard 1977), and it is possible that the same may be true for Pasilobus (Robinson and Robinson 1975). It is interesting to note that the tendency of Pasilobus to lay the frame lines by floating them downwind of the spider's eventual resting site would make its nearly horizontal web lie downwind of the spider, and at least as long as the wind direction did not change this would be the direction from which moths being attracted chemically would be expected to approach.

D Both M. dizzydeani and Pasilobus produce sticky silk which adheres firmly to moths, something which no other araneid is known to do. Their sticky silk seems to differ in that Pasilobus silk will stick repeatedly while that of $M$. dizzydeani loses most of its stickiness after the first contact.

E Both M. dizzydeani and Cyrtarachne sp. release an unpleasant odor when handled, a characteristic unique among araneids and perhaps all spiders. Species of all four genera rest in very exposed sites during the day with their legs folded tightly around their bodies so their front legs cross under the anterior part of the cephalothorax, a posture unusual in araneids.

In addition to these links between $M$. dizzydeani and Pasilobus, Poecilopachys, and Cyrtarachne, there are also behavioral links between M. dizzydeani and Celaenia and Taczanowskia:

A All three seem to specialize as adults on male moths as prey (McKeown 1952, Eberhard in press). Capture of small flies by spiderling $M$. dizzydeani is also parallelled in Celaenia sp. since C. S. Lauder has found over 300 spiderlings of this species feeding - all on male psychodid flies (C. S. Lauder, pers. comm.).

B Both Celaenia excavata and Taczanowskia sp. (Eberhard in press) seem to spin no web other than a single dry horizontal 


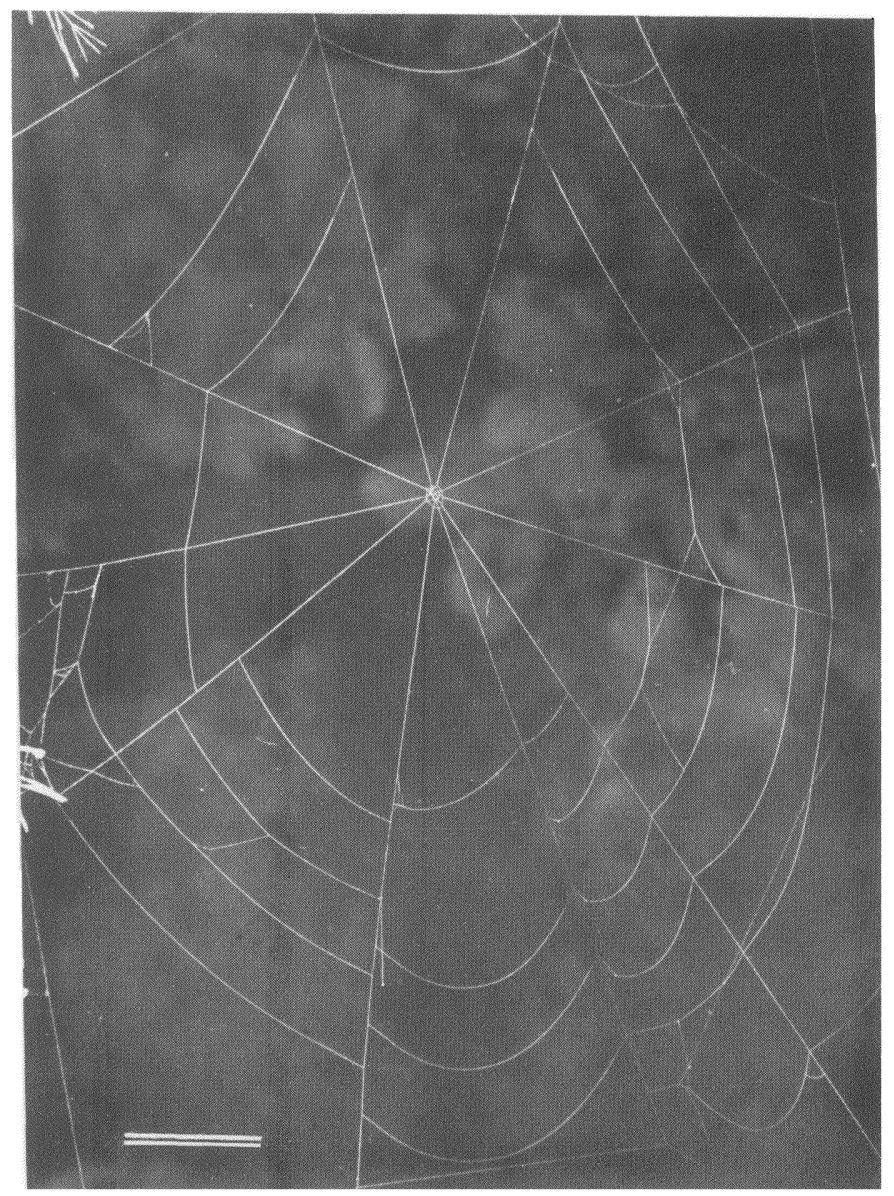

Fig. 18. Web of mature female Cyrtarachne sp. (scale marker $=5 \mathrm{~cm}$.).

line, and $M$. dizzydeani also sometimes limit its spinning to this minimum and assumes a similar hunting posture.

C The egg sacs of species in all three genera are more or less round and tear-shaped, with very strong outer layers (Gertsch 1955, McKeown 1952, Forster and Forster 1973, Eberhard in press), an unusual design for araneids. The construction behavior of Celaenia excavata (Lowry in McKeown 1952) is nearly identical that of $M$. dizzydeani. 
D Both Celaenia (Forster and Forster 1973) and Taczanowskia (Eberhard in press) adopt the same daytime resting posture as that of Mastophora.

In sum, the data suggest that the traditional groups of Cyrtarachneae (including Cyrtarachne, Pasilobus, Poecilopachys, and four other genera), Mastophoreae (including Mastophora, Dichrostichus, Cladomelea, and three other genera), and Celaenieae (including Celaenia and Taczanowskia) (Roewer 1942) should be placed together in the same section of the subfamily Araneinae.

It is reasonable to ask why natural selection would favor such radical reduction in trapping webs in this group. The use of volatile substances mimicking prey pheromones could make large traps superfluous, and one can imagine a gradual reduction in webs accompanying an increasingly precise mimicry. The development of an adhesive capable of restraining moths could also result in selection for simplified webs designed to maximize prey interception efficiency (Chacón and Eberhard 1980). It is not immediately clear however why an effective sticky trap like a bolas should be abandoned altogether as in Celaenia, Taczanowskia, and, on occasion, $M$. dizzydeani. It seemed that wind conditions may have influenced the type of trap M. dizzydeani used, since the most elaborate web (three balls) was made when the air was unusually still, and spiders apparently hunted without balls during particularly windy periods. Under windless conditions a more elaborate trap might be advantageous since 1) an attractant would diffuse in many directions and the direction from which prey might approach would be less certain, and 2) the sticky material would be especially effective since it would not dry out as quickly. On the other hand, strong wind (or relatively dry conditions of any sort, including relatively small body size) would make investment in sticky material which evaporated quickly less advantageous. As noted above, this line of reasoning could also explain the apparently greater frequency of hunting without balls in younger $M$. dizzydeani.

This consideration may have consequences regarding the as yet unestablished trapping method of newly emerged $M$. dizzydeani. If my observations of spiderlings apparently hunting without a bolas are typical and correctly interpreted, then they may provide an explanation for the rows of bristles on the inner sides of the anterior legs of spiderlings (and incidently suggest that mature males, which also have these bristles, may feed after they mature; perhaps, as 
Gertsch 1947 suggests, they can live for extended periods). It is interesting to note that Celaenia, which hunt without a web, also have spines on their front pairs of legs (e.g. Fig. 24 in Forster 1967). In this case however the spines are on the ventral surfaces of the femur and tibia, and would seem designed to give the spider a more secure grip on prey that has already been seized (see however Lowry's description in McKeown 1952 of spiders accepting prey held in forceps) rather than to increase the surface of the leg and thus presumably its ability to intercept prey as in small $M$. dizzydeani.

The variety of prey captured by $M$. dizzydeani (Table 1) is not surprising, given the fact that different moth species have been found to use identical sex attractant chemicals (e.g. Silberglied 1976). It is however unexpected to see the differences in prey captured by different individuals of the same species and size at the same time and place. The spiders seem to be somewhat flexible with regard to prey, and this trait could obviously be advantageous if, as seems likely, a single prey species is not consistently plentiful. How the differences between individual spiders are produced is unknown. Although the data are meager, it appears probable that $M$. dizzydeani change pheromones as they mature, attracting larger species as they grow. This conclusion must remain tentative however pending more data on prey, proof that the other prey species actually produce and respond to different pheromones, and that the spiders attract them chemically. Perhaps the thick-walled egg sacs of Mastophora and its relatives serve to protect the young for extended periods so that they can emerge when particular prey species are abundant.

The name "bolas spider" is firmly fixed in the literature, and I do not propose that it be changed, but it is worth noting that it is a misnomer for Mastophora. A bolas consists of a thong or thongs to which heavy balls are attached, and is thrown so that the thong wraps around the target, impeding its escape. The Mastophora trap is more sophisticated: it depends on the extraordinary stickiness of the ball rather than the entangling action of the line; it is swung rather than thrown at the prey; and the ball itself converts reversibly into a sticky line which increases the spider's striking distance. A less picturesque but more accurate name would be "sticky yo-yo spider".

\section{ACKNOWLEDGEMENTS}

I thank R. Forster and C. S. Lauder for information on Celaenia, 
Carlos and Olga Hobrecker for their hospitality at Lago Calima, A. J. T. Johnsingh and M. Gadgil for help and hospitality in India, Willis Gertsch for examining specimens of the spider, H. W. Levi for help with materials, R. W. Work for kindly examining specimens of the bolas and allowing me to use his photographs and unpublished data, H. Dahners for help with the moths, and M. J. W. Eberhard for a critical reading of the manuscript. Financial support was provided by the Comité de Investigaciones of the Universidad del Valle, Cali, Colombia, and the Vicerectoría de Investigacion, Universidad de Costa Rica.

\section{SUMMARY}

The form of the egg sac, variations in bolas construction and hunting technique, and other behaviors link Mastophora dizzydeani sp.n. to both reduced-orb weavers (Cyrtarachneae) and webless araneids (Celaeneae). The sticky ball is structurally complex, and includes both a substantial portion of volatile liquid and a mass of flattened, apparently spring-like thread; it elongates reversibly when it is swung.

There was significant variation between individual spiders with respect to the species of moths that they captured. Adult females converted about $35 \%$ of the weight of their prey into eggs. They produce an unpleasant odor when handled. Newly emerged spiderlings apparently hunted without making a bolas, and preyed on small nematocerous flies. Males did not emerge already mature from egg sacs, and it may be that cannibalism within egg sacs accounts for the emergence of mature males in other species.

\section{Literature Cited}

Akerman, C. 1923. A comparison of the habits of a South African spider, Cladomelea, with those of an Australian, Dichrostichus. Ann. Natal Mus. 5: 83-88.

Chacón, P. and W. G. Eberhard. 1980. Factors affecting numbers and kinds of prey caught in artificial spider webs, with considerations of how orb webs trap prey. Bull. br. arachnol. Soc. 5(1):29-38.

Clyne, D. 1973. Notes on the web of Poecilopachys australasia (Griffith and Pidgeon, 1883) (Araneida: Argiopidae). Aust. ent. Mag. 1: 23-29.

EBERHARD, W. G. 1976. Physical properties of sticky spirals and their connections: sliding connections in orb webs. J. nat. Hist. 10: 481-488. 1175 .

1977. Aggressive chemical mimicry by a bolas spider. Science 198: 1173- 
1979. Rates of egg production by tropical spiders in the field. Biotropica 11(4): 292-300.

1980. Spider and fly play cat and mouse. Nat. Hist. 89(1): 56-61.

in press. Notes on the natural history of Taczanowskia sp. (Araneae: Araneidae). Bull. br. arachnol. Soc. 5(4).

Eisner, R., R. Alsop, AND G. Etrershank. 1964. Adhesiveness of spider silk. Science 146: 1058-1061.

Forster, R. R. 1967. The Spiders of New Zealand. Part I. Otago Mus. Bull. No. 1: $7-124$.

Forster, R. R., AND L. Forster. 1973. New Zealand Spiders. London: Collins

GerTsCH, W. 1947. Spiders that lasso their prey. Nat. Hist. 56(4): 152-158, 189.

GertsCh, W. 1955. The North American bolas spiders of the genera Mastophora and Agatostichus. Bull. Am. Mus. nat. Hist. 106(4): 221-254.

Hutchinson, C. E. 1903. A bolas-throwing spider. Sci. Am. 89(10): 172.

Longman, H. 1922. The magnificent spider: Dichrostichus magnificus Rainbow. Notes on cocoon spinning and method of catching prey. Proc. roy. Soc. Queensland 33: 91-98.

McKeown, K. C. 1952. Australian Spiders. Sydney: Angus \& Robertson.

Robinson, M. H. 1969. Predatory behavior of Argiope argentata (Fabricius). Am. Zool. 9: 161-173.

Robinson, M. H. AND B. Robinson. 1975. Evolution beyond the orb web: the web of the araneid spider Pasilobus sp., its structure, operation and function. Zool. J. Linn. Soc. 56(4): 301-314.

Robinson, M. H., B. Robinson, AND W. Graney. 1972. The predatory behavior of the nocturnal orb-web spider Eriophora fuliginea (C. L. Koch) (Araneae: Araneidae). An. Primer Congr. Latinoam. Ent. Rev. peru. Ent. Agric. 14: 304315.

Roewer, C. F. 1942. Katalog der Araneae. Bremen, 1: 1-1040.

Silberglied, R. 1976. Communication in the Lepidoptera. in T.A. Sebeok (ed.) How Animals Communicate. Bloomington, Ind.: Indiana Univ. Press, pp. 362402. 

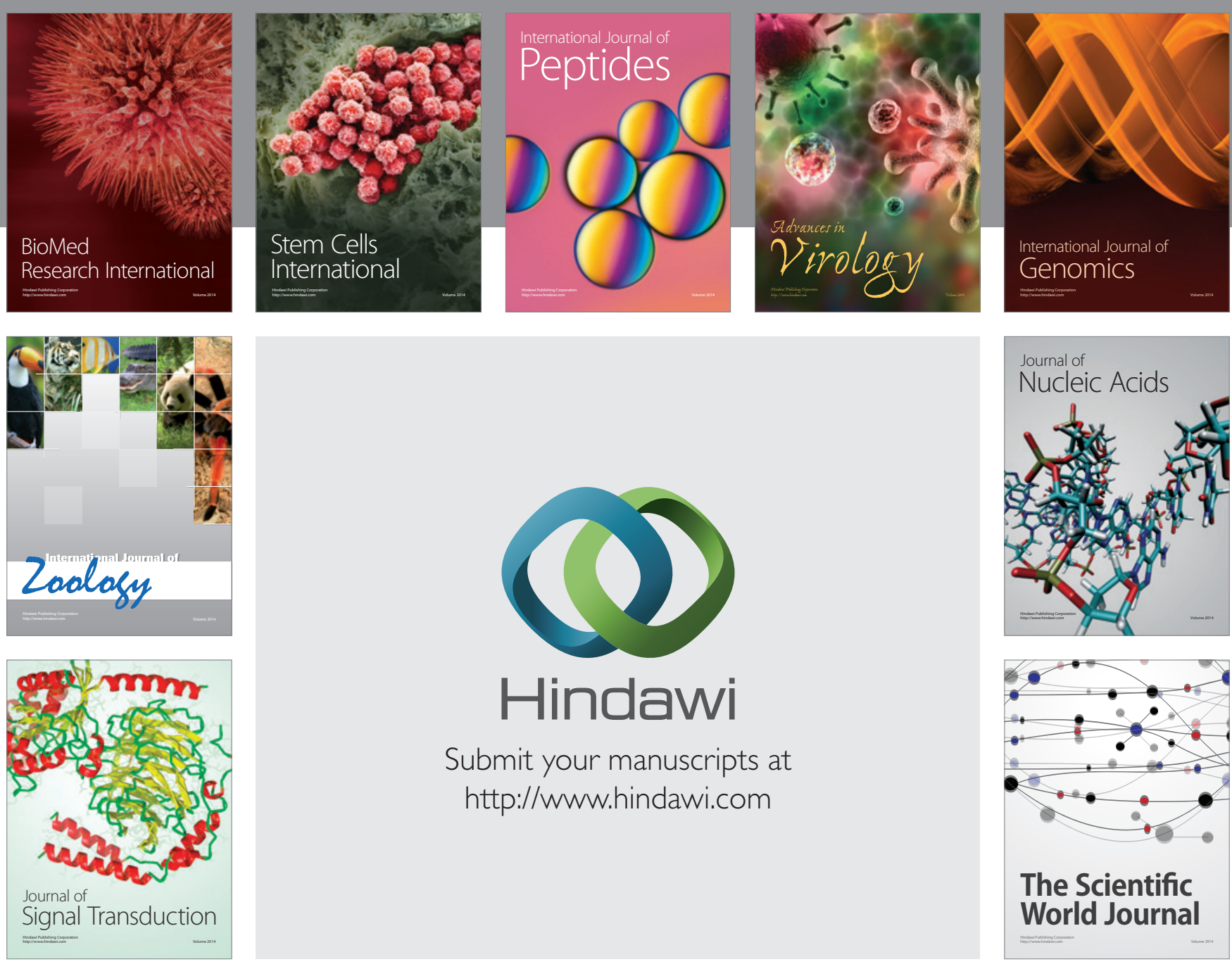

Submit your manuscripts at

http://www.hindawi.com
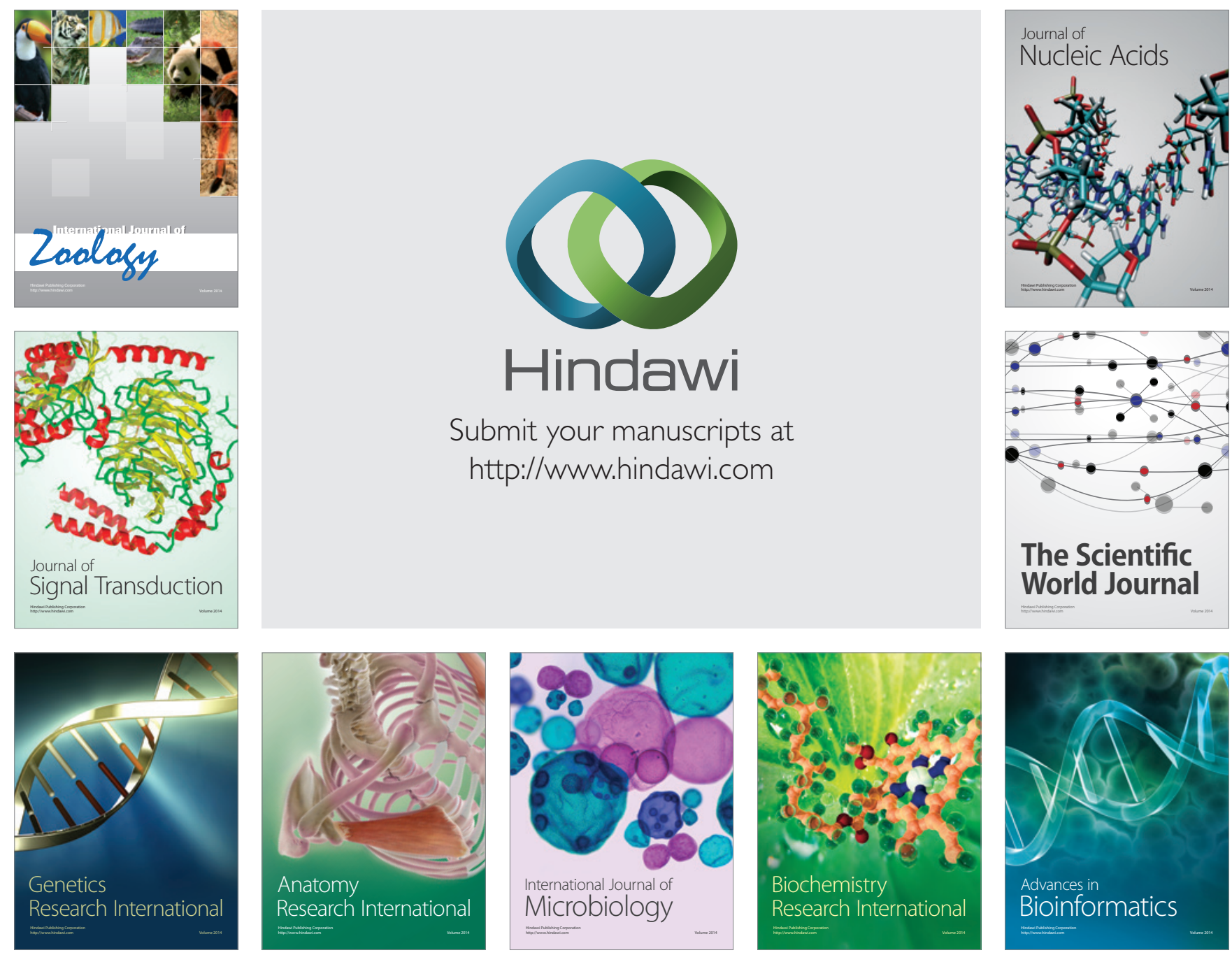

The Scientific World Journal
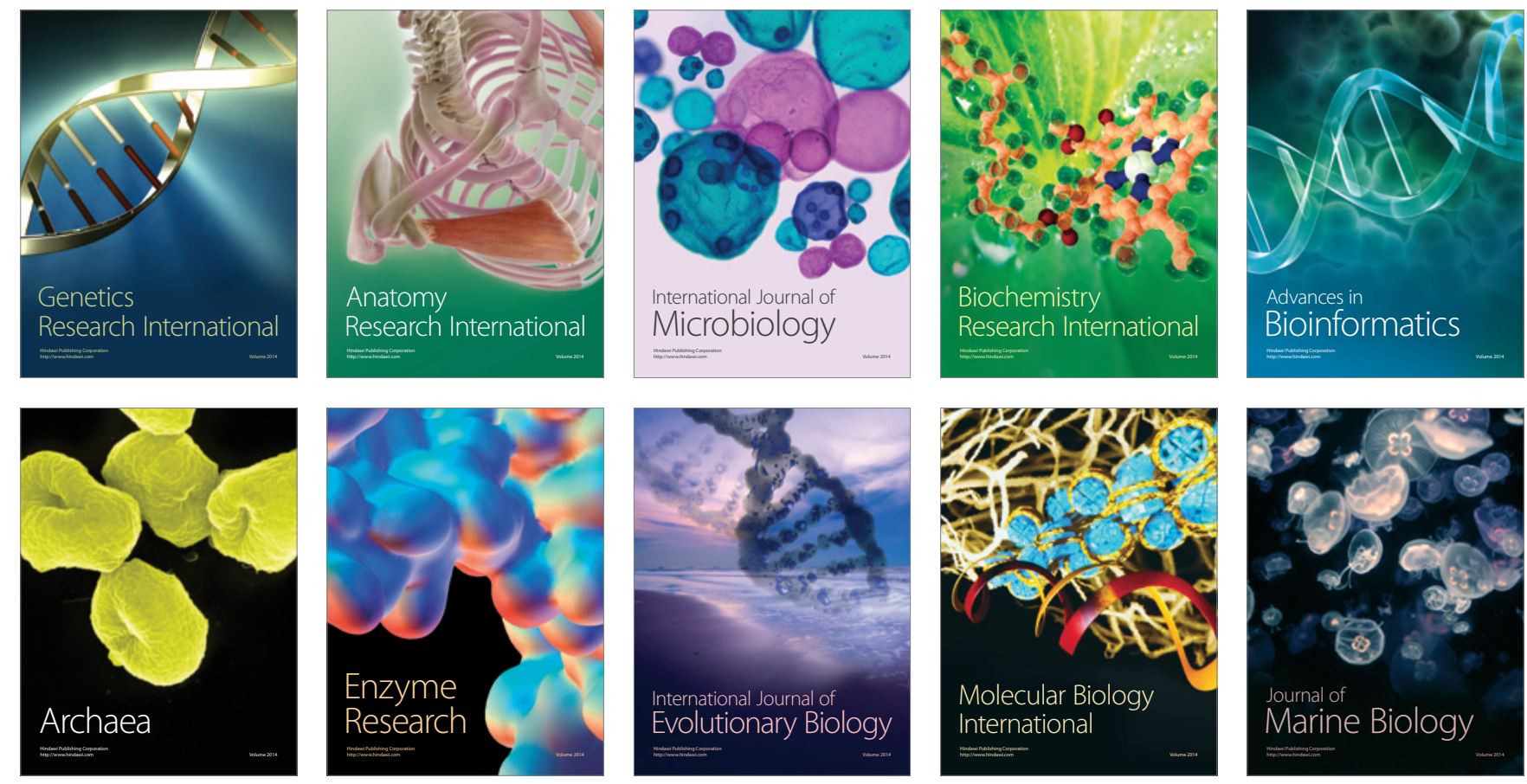